Arqueología y Sociedad,

№ 22, 2010

\title{
ETNICIDAD, TIPOLOGÍA SOCIAL Y LITERATURA
}

\author{
Rommel Plasencia Soto*
}

\section{Resumen}

En este artículo se discute el concepto de etnicidad en la antropología social y además incluimos algunos ejemplos de tipologías sociales encontradas en algunas novelas que interesan al autor.

\section{Palabras clave}

Etnicidad, etnografía, tipologías sociales, literatura.

\section{Abstract}

With something freedom we try to discuss the concept of ethicity in the social anthropology and besides incluide some examples of social types found in some novels taht interest the author.

\section{Keywords}

Etnhicity, etnography, social types, literature.

* Universidad Nacional Mayor de San Marcos.

Correo electrónico: rplasencia@hotmail.com 
La etnicidad ofrece quizás las mismas dificultades que tienen otras categorías para explicar realidades múltiples de aquellas sociedades frecuentemente estudiadas por la antropología. Aunque parezca paradójico, la "pequeñez sociológica” de estas realidades generaron mayores dificultades que certezas para comprender su funcionamiento, mucho más que las denominadas sociedades de "gran escala" según lo ha expresado Burton Benedict (1980).

Y esto se debe a que la antropología tradicionalmente se involucró en el examen de sociedades tribales y campesinas o de su incrustamiento en las ciudades. Las sociedades que experimentaron la "gran transformación" que produjo la revolución industrial, al ser examinadas por la sociología y la economía política, dedujeron categorías consideradas "duras", controlables, con contenidos precisos y hasta cierto punto, previsibles.

Así, capital, salario, clases sociales, acumulación, plusvalía, movilidad social o secularización, fueron rápidamente entendibles y muy útiles para entender los mecanismos sociológicos -y hasta cierto punto, simbólicos- que explicaban la dinámica de las sociedades complejas.

Ha sido Pitt-Rivers (1976) quien relacionó la dificultad que representaban estas realidades multiformes de las que se ocupa la antropología y las categorías diseñadas para su entendimiento. Potlach, Tabú, o Totemismo eran dotados de contenidos confusos, relacionales y limitados en el espacio e imposibles de ser utilizadas universalmente, es decir, trascendidas de su contenido local.

Precisamente el antropólogo de Oxford ha ilustrado como posible el espejismo producido por las descripciones de puritanos, misioneros y cazadores, sobre la naturaleza del potlach en el noreste americano, y la pertinencia de extrapolarla a otras realidades etnográficas, definida como un supuesto derroche "orgiástico" y "dionisiaco".

Utilizando la ironía al examinar el concepto de casta en la teoría etnológica, dice que a su "defunción en términos etnográficos le siguió una resurrección por parte de los antropólogos". Usada para describir sistemas de estratificación social tan lejanos del paisaje indio como el sur de los Estados Unidos o la América colonial, según Pitt-Rivers, la palabra no soportaba la comparación.

Se intentaba equiparar un sistema cerrado con otros considerados abiertos; mientras la ascendencia y la pureza eran fundamentales en el sistema hindú, en América lo era la descendencia y la mezcla. Creemos que igual suerte ha corrido el concepto de etnicidad. Sobre todo, en los países de América Latina donde las sociedades complejas como las de "pequeña escala" no sólo han convivido, sino que se han articulado, produciendo realidades claroscuras y multiformes.

En el Perú para sortear esta situación, se habló en algún momento, de realidades "coloidales", de "mosaico" o de "archipiélago de situaciones sociales y culturales", especies de conceptos similares al de verticalidad transvertidas para el Perú del siglo XX y XXI ${ }^{1}$. Como si la indefinición sirviese de muleta conceptual para definirnos como colectividad. Es en ese sentido que discutiremos las particularidades de lo étnico y de la identidad étnica en nuestro país.

\section{UN CONCEPTO ESQUIVO}

El concepto de etnicidad como herramienta analítica para entender un país como el nuestro y por extensión el de los países andinos, ha ido variando en su contenido, en su ámbito y en sus orígenes. Es indesligable por una parte, de nuestra llamada "herencia colonial", es decir de factores plenamente históricos, y de otra, de la renovación de dicho concepto en las ciencias sociales.

Sobre todo a partir de la célebre introducción de Barth a Los grupos étnicos y sus fronteras

1 Del mismo modo, Sábato habla de la Argentina como "babilónica", para referirse a sus orígenes múltiples y que impiden según el novelista, una colectividad unificada. Este pesimismo se desliza sobre todo en Sobre Héroes y Tumbas. 
[Ethnic groups and boundaires. The social organization of culture difference, 1969], es que la etnicidad es vista como un proceso de negociación y de interrelación entre grupos discretos.

En tal sentido la identidad étnica no puede ser definida en términos absolutos, sino únicamente en relación a un sistema social determinado. Ha sido Richard Adams (1993), con una larga -y hay veces polémica- trayectoria de estudios étnicos en Guatemala, quien ha desarrollado un elocuente modelo en la que se puede apreciar la complejidad de lo étnico y que nos convence de que este concepto efectivamente es relacional y móvil.

Adams considera que la etnicidad posee una dimensión externa y otra, interna. Ambas esferas pueden delimitar grupos de referencia distintos, pues atienden a indicadores diferentes. Los indicadores externos son visibles para el observador y pueden ser utilizados por el propio grupo como "rasgos diacríticos."

Los indicadores propios de la etnicidad interna son más íntimos y solo reconocibles por los miembros del grupo. Muchas veces son considerados como los "verdaderos rasgos" de adscripción étnica. Ambas esferas a su vez, poseen una dimensión "objetiva" y otra "subjetiva”. La primera, ocupa un papel importante para los observadores, aunque estos últimos -los extraños- pueden seleccionar características que se presumen adecuadas, dejando de lado los rasgos que los miembros del grupo consideran propias. La auto-adscripción que hacen los miembros de un grupo puede delimitar un conjunto distinto de lo que podrían delimitar los observadores. ${ }^{2}$

2 Es el caso del conjunto arahuaco en el piedemonte amazónico. Los colonos y misioneros católicos los denominaron genéricamente "campas". Pero cada subconjunto tiene un etnónimo inclusivo que como una fuente irradiada va desde el grupo básico de parentesco, las alianzas a lo largo de una cuenca y luego al grupo en general, como sucede con los ashaninkas. Sin embargo según Weiss (2005: 6-7) los lingüistas han creado artificialmente grupos distintos que en sí, son unitarios. Por eso el decide volver a llamarlos "campas", aunque él aclara que esta vez su uso es académico y no prejuiciado.
De este modo, para un ladino o para un mestizo, todos los que viven en el campo y se dedican a la agricultura pueden ser nominados de "indios", pero estos últimos pueden distinguir a los individuos de su grupo de lo no-indios que viven en áreas rurales.

La definición "interna" de la etnicidad se refiere como sabemos, a la auto-adscripción, es decir la que los mismos actores sociales consideran significativas y en que los elementos importantes son el parentesco y el lenguaje, que van delineando los límites sociales, territoriales y simbólicos. En definitiva, las etnicidades "internas" son el fundamento de la identidad y las externas, son las categorías étnicas que sirven como mecanismos de evaluación.

\section{UN CONCEPTO RELACIONAL}

A estas alturas podemos deslizar algunas ideas acerca de la cuestión étnica en el Perú. Es a partir de los años 80, que el establishment de las ciencias sociales peruanas, aprovechando de la "caída del muro” abjuró del compromiso histórico.

Su consecuencia más inmediata fue el llamado "regreso del sujeto" aunque mirada ahora a la distancia, pareció más bien una "omnipotencia del sujeto", al minimizar las estructuras sociales y disociar el presente con el pasado.

La realidad prefirió ser vista como un "estallido en pedazos" antes que su potencialidad totalizadora, a la vez que se opacó el concepto que se tenía del capitalismo en el mundo de hoy.

No debemos pues en ese sentido, minimizar la tutela académica norteamericana sobre América Latina (sobre todo en las universidades privadas y los organismos no gubernamentales de desarrollo), incluida sus corrientes más "radicales".

Entre otros efectos que esto tuvo, fue el de evitar el sólido esfuerzo comparativo usual en la antropología, al no cotejar lo que nos sucede con África o Asia por ejemplo. El otro, fue volver nuevamente al ciclo de la cultura como 
clave explicativa, obviando la mirada más dinámica del concepto de sociedad. ${ }^{3}$

Del mismo modo, se empezó la crítica general al positivismo y del que se suponía el marxismo era tributario. Ante ello se alentaron los métodos humanistas y "comunicativos" que tenían una relación más solidaria con los sujetos de investigación (Cortázar 1992).

Con el paulatino desplazamiento del concepto de clases sociales y el uso más frecuente de las categorías étnicas, se concilió con lo que pasaba en otros cielos. El Estado de bienestar que se moderniza en los años 50, pierde representatividad. Su decaimiento, ya no puede garantizar por ejemplo, el empleo, la urbanización o la "aculturación" de los éxodos rurales. Es en ese contexto que se "visibiliza" la cultura, sobre todo en el ámbito del consumo y la hibridación social.

Sin embargo, hoy se atribuye a los grupos étnicos la misma coherencia que antes se la rechazaba en las clases sociales. Es más, muchas veces hemos asistido al invento o sobreestimación de realidades étnicas, cuando en realidad eran movimientos sociales amplios. Por supuesto que la identidad étnica era muchas veces ideológica (íconos, símbolos, discursos, etc.) y que no necesariamente estaban adscritas a corpus sociales. ${ }^{4}$ Podría también ser generada por la ansiedad de las clases medias profesionales que parece ser el principal espacio de reproducción del discurso étnico intelectual, muy ajeno por supuesto al sentido igualitario que implica una construcción nacional desde sus raíces históricas y de reducción de las desigualdades.

Muchas caracterizaciones étnicas son el resultado de agendas políticas que recurren a la "tradición" o la "autenticidad cultural" para cohesionar a los grupos en conflicto, lo cual mu-

3 Una interesante crítica a los invasivos "estudios culturales" puede verse en Reinoso (2000) y el trayecto del concepto de cultura en la antropología norteamericana en Kuper (2001)

4 En el caso boliviano, se han sobre ofertado los matices "étnicos" de un movimiento social muy amplio y disímil, que llevó a Evo Morales al poder. Véase Stefanoni (2007). chas veces refuerza la idea de que la etnicidad es "inventada".

Tomemos como caso el movimiento Hindutva en la India, que ha singularizado en su discurso nacionalista el periodo previo a la conquista musulmana, para restaurar el "clasicismo hindú" en desmedro del arraigado secularismo y multirreligiosidad en la India de hoy. Para ello ha recurrido no sólo a la falsificación histórica sino también lamentablemente, a los zarpazos de violencia como lo sucedido en Gujarat en el 2002.

Escribimos esto a propósito de la ficción sociológica de supuestas revalorizaciones culturales indígenas o vuelta a las raíces "quechuas" o "aimaras" de grupos electorales que lo único indígena que poseen quizás sean sus siglas o el atuendo de sus líderes.

Otro punto es la formulación de Van den Berghe (1973) al evaluar el papel problemático de la terminología socio-étnica en muchas monografías peruanas.

Pues finalmente se pregunta si la disparidad de los términos utilizados (cholos, indios, mistis, wiracochas, mozos, chutos, criollos, etc.) se deben a la diversidad de situaciones sociales o a los caprichos semánticos del autor. También discute los indicadores a tomar en consideración. ¿La raza? iLa cultura? iLa clase social? iSe privilegian sus aspectos objetivos? ¿Subjetivos?

No olvidemos también la situación social en que el etnógrafo hace su indagación. Es muy probable que si históricamente, la comunidad del investigador sea ajena al grupo que estudia, privilegiará el inventario de rasgos culturales. Pero si su grupo ha interactuado con el conjunto estudiado -como es el caso de los antropólogos afrikaners o los mestizos de América Latinaprivilegiarán las relaciones interétnicas, generalmente conflictivas.

Las categorías étnicas en general definen la relación. Sirven para definir al otro, pero también sirven para definirse a si mismo. Ello implica también definir la relación que uno mantiene con los demás. 


\section{Discutir la etnicidad en el Perú}

Uno de los problemas existenciales de nuestra narrativa histórica, es el llamado "problema indígena" percibida como una "falla" de la República.

En un primer momento, fresco aún el impulso paternalista heredado de la colonia, nuestro complejo de culpa fue la incapacidad de integrarlos a la Nación. Luego, fue la incapacidad de los propios indios para modernizarse. De igual modo, se construyó una imagen demasiado simplificada de los mestizos, que redujeron la riqueza y pluralidad de sus situaciones a costa de una sola característica: la modernidad.

Aquí igualmente hubo dos momentos. En el primero, el mestizo es el enemigo del indio. Casi toda la literatura indigenista o post-indigenista es anti-mestiza por excelencia, desde Tempestad en los Andes - pasando por Raza de Broncehasta Todas las Sangres. ${ }^{5}$ En el segundo, con los estudios pioneros sobre la informalidad urbana, el mestizo es vaciado de su contenido cultural y dotado de una ciudadanía moderna, para ser el agente del capitalismo popular. El cambio de óptica tiene que ver con que la modernidad fue percibida primero como una amenaza de la tradición y luego, como aliada y reproductora de la herencia cultural.

Aunque en general, los mestizos han sido vinculados a una modernidad que pertenece al futuro, pero que debía dejar atrás el pasado. Los indígenas por el contrario han sido vistos como los depositarios de la tradición y pertenecientes a un pasado sin un futuro.

La paradoja es que muchos logros del mestizaje andino (sobre todo en el arte y el folklore) han pasado para los observadores externos como “indígenas/andinas", dejándonos una vez más la

5 Esta "reversión cultural" como la ha llamado Lauer (1997) permitió a los intelectuales indigenistas ser modernos, tomando como insumo lo mas "tradicional" de la sociedad peruana. Los novelistas mestizos al narrar, usurparon el lugar o suprimieron la voz del otro (el mestizo iletrado y el indígena) para hacerse sujeto dominante y quizás único del texto. sensación de que lo "indígena" o lo "mestizo" son una especie de mapas sin realidades. ${ }^{6}$

Por ejemplo, los grupos étnicos de la amazonia son los excluidos del concepto del mestizaje, su modernización económica es políticamente incorrecta pues sustrae al moderno etnógrafo de su laboratorio natural. Esto es real tanto para el activista del desarrollo como para el estructuralista francés. Sin embargo agregaremos que el discurso racista y sus prácticas descansan entre otras cosas en la ideología del mestizaje, aunque este es usado más bien en el espacio privado y social que en el político.

Quizás con los sucesos de Bagua en junio del 2,009, es que se haya inaugurado la convergencia entre la auto-organización étnica y la lucha política. Por eso su peligrosidad para la clase política peruana, generalmente conservadora.

Creemos finalmente, que no hay una sino muchas modernidades indígenas. Desde la "sensibilidad por la moneda" necesaria para pagar las cargas fiscales (Contreras 1988), pasando por la conversión religiosa del siglo XVII, las migraciones del siglo XX, el protestantismo andino? ${ }^{7}$, el capitalismo de base popular y la autodeterminación étnica de la amazonia peruana.

\section{¿Por Qué el Perú no?}

Otro asunto es una pregunta traumática que se ha vuelto recurrente: iporque a diferencia de Bolivia o Ecuador, no hay un movimiento indígena en los Andes peruanos?

6 Es el caso de la música huamanguina o la música de Cochabamba (Bolivia), ambas dotan de identidad a regiones "andinas". Constituidas en base al desarraigo, la frontera, la migración y la nostalgia, se nos revelan como planos de individuación propios del mestizaje. Para un cancionero de la música ayacuchana, véase García (1991).

7 Una de las mejores etnografías sobre el protestantismo en áreas indígenas que he leído, es el de Carlos Garma (1988). Sólo en la medida en que una religión cambia las relaciones entre los individuos, es que produce un cambio social. El catolicismo andino fue más bien epidérmico y permitió muchas simbiosis. 
O ampliando la interrogante, porque no lo hay, cuando en el resto de países del continente con población indígena, se ha asistido a importantes modelos organizativos (México, Guatemala, Chile) o de grupos subalternos con o sin tinte étnico (la negritud antillana y caribeña, el MST brasileño).

Traumática, porque nos deja fuera de los importantes movimientos sociales de fines del siglo XX, y también porqué deja mal parada a las ciencias sociales peruanas, que pugnan cada cual por explicar el porqué de esta "anomalía," y el ejercicio es doloroso, pues afecta a la propia comunidad intelectual.

Doloroso porque desperezado el diván, nos damos cuenta que en ella confluyen no sólo los límites de la antropología peruana, sino también nos revela la crisis de algunos paradigmas centrales de la disciplina.

Pero esta vez no es una crisis epistemológica desde el Norte, inducida por una catarsis colectiva, que los exorcizaba de ser antropólogos, blancos y ricos como sucedió con los discípulos de Geertz.

En primer lugar esta el acoso de saber que es -pregunta decimonónica- el indio. Algo más, una vez sabido, como señalarlo en una determinada sociedad. En un interesante trabajo (Pajuelo 2006) se refiere a la "elusiva condición de indio en la sierra peruana".

Anotando la situación "laberíntica" de las identidades étnicas, término prestado de Max Hernández cuando este se refiere a la identidad del inca Garcilaso. La interrogante de Pajuelo es pues válida.

Ya en otra comunicación (Plasencia 2007) hemos enunciado que la noción de indio puede ser vista bien como una categoría supra-étnica, en la cual la relación social es la que le confiere alteridad (como lo han señalado Bonfil Batalla o Favre) o el de estar circunscritos a taxonomías locales en las que el concepto de etnicidad va unido al de territorialidad.

La dificultad de esta última propuesta es que se pierde el necesario criterio de totalidad y unicidad. Su ventaja es que esta detallada en cientos de monografías de pueblos y regiones de los Andes, algunas poco útiles pues envejecieron rápidamente.

¿Riobamba es la misma que Burgos examinó? ¿Muquiyauyo cedió a las posiciones de clase y modernización que avizoraron Adams y luego Grondin? ¿Pisac sigue teniendo en los mozos su carta adecuada para un equilibrio entre indios y no indios tal como lo planteara Hernán Castillo?

Difícil saberlo. Esto se complica más, si utilizamos el libre criterio (isi quiero, soy indio!) frente a las frías razones sociológicas en la que los grupos étnicos están auto-organizados independientemente de los observadores o de la opinión de sus miembros (por ejemplo, las zonas rurales de Huancavelica son generalmente indias).

La primera es una propuesta importada de los países nor-atlánticos en que la afirmación individual es importante en sociedades atomizadas o con sub-conjuntos laicos. Con la segunda, tropezaríamos con la negativa de muchas poblaciones a auto-adscribirse de indios o por la debilidad de los indicadores.

Por ejemplo la lengua quechua es fundamentalmente un fenómeno geográfico que cultural. La miscegenación ${ }^{8}$ ha sido intensa y continúa en los Andes; pues en los departamentos considerados "indios", se superponen capas de sectores mestizos o blancos. Quizás los límites sociales sean útiles.

Los arreglos expresados en el parentesco, las alianzas matrimoniales, el compadrazgo, las etiquetas inter-grupos, el mercado y el poder político son mas interesantes. En general, los grupos indígenas construyen sus vínculos sociales hacia adentro y de los mestizos se espera que las expandan. Con esto volvemos a los estándares clásicos de la antropología social, pero que decaen cuando los indígenas migran a contextos urbanos y multiculturales.

8 Con este término nos referimos a la mezcla racial en América Latina. 
Definitivamente, el Perú no asiste a movimientos indígenas en las sierra por estas razones que operan a manera de hipótesis:

\section{1. "La izquierda no pensó lo étnico".}

Posiblemente la izquierda peruana al hablar y movilizar al campesino peruano, le confirió un carácter de estrato social antes de pensar en su sustrato étnico. Vanguardia Revolucionaria por ejemplo una escisión del viejo partido de Acción Popular, retuvo su orientación agrarista y por eso fue cómodo a muchos antropólogos militar en ella, quienes así combinaban su profesión con sus ideales políticos.

Por eso no sorprenden cuando analizan las movilizaciones campesinas en Andahuaylas en 1973. Describen todo; menos la condición de indígenas de los feudatarios en un contexto particular. También el gobierno militar de Velasco al incorporar intelectuales de izquierda, incorpora esa visión del campesinado como clase.

Aún hoy, cuando releo Cuzco: Tierra y Muerte, me sorprende que haya sido Neira (1964:107) -un historiador/periodista - quien haya sospechado que la cama vacía que guardaban los campesinos para Hugo Blanco, poseía una connotación mesiánica y de respeto casi religioso. Observación que contrastaba con el discurso jacobino que se gestaba en los estudios de abogados del Cuzco.

Al no incorporar la reivindicación étnica en su plataforma política, quizás convenció a las comunidades y sujetos andinos, de que esta no existía, y cuando la izquierda la pensó, esta casi ya no existía.

\section{2. "Los no indígenas manipulan los símbolos indigenas"}

Esto sucede quizás ejemplarmente en los Andes peruanos. Es la única área cultural en donde el misti $^{9}$ comparte el utillaje cultural del campesi-

9 Se puede definir al misti como al no-indio en general y sólo en oposición a este. La etnografía andina le da un nado indígena.

La lengua quechua como sabemos, fue utilizada por gamonales y hacendados para expoliar al indio. Es más, sus hijos radicalizados en la universidad, ante la amenaza de costeños y extranjeros como nuevos amos del comercio, trataron de formalizarlo en sendos diccionarios (y de paso recopilaron su folklore).

Muchas fiestas indígenas han sido y son sufragados por los mistis. Ambos comparten el entusiasmo religioso que se vive en el catolicismo andino y muchos creen en los Apus. Favre lo reporta para Moya. El autor de este artículo escuchó contar a un ex-hacendado lirqueño (región de Huancavelica), que salía a cazar venados con un pongo y ofrendaban una mesa al Wamani en las laderas de Utcuy, para propiciar una buena jornada.

Esto es imposible de reconocer en Mesoamérica. Un ladino no habla lengua indígena alguna (a menos que sea un lingüista o un antropólogo), ni comparte fiestas, ni creencias de origen prehispánico. Sería poco probable por ejemplo, que un ladino de Chiapas para sortear la suerte, recurra a un ch'abajom tzeltal.

Esta característica en la sierra peruana, quizás impidió no solo el radicalismo indígena sino también, su organización autónoma.

Por eso la antesala de la Revolución Mexicana en el sur indígena, fue la llamada "guerra de castas” de Yucatán en 1847. Dos grupos distintos e irreconciliables enfrentándose en una guerra de exterminio.

Al respecto, Nelson Manrique (1988: 157162) nos ofrece un modelo explicativo sobre este asunto. Tratando de ampliar el esquema del "triángulo sin base" de Cotler, el autor repara

colorido despliegue de contenidos. Favre (1983/85) los llama petit blancs para Moya en el norte de Huancavelica. Ossio (1978) distingue al chahua misti (misti crudo o falso misti) del verdadero misti en Andamarca, al sur de Ayacucho. Lo importante es que no sólo el factor racial esta descartado en su definición, sino que a sus variables de distinción, es gravitante su estrecha relación con los indígenas en un contexto de pugna y dominación. 
que en aquellas zonas en las cuales existía una distancia socio-económica entre indios y mistis, se imponía una cercanía cultural. Y en donde esta se reducía -como en el valle del Mantarose ampliaba la brecha cultural. Esto último lo grafica con las censuras a las fiestas "indígenas" que se practicaban en la ciudad de Huancayo, de parte de comerciantes huancaínos parapetados en el gobierno municipal.

Por último, muchas instituciones indígenas como los varayos y los ayllus, permitían "la permanente renovación de la relaciones de reciprocidad" en beneficio de las haciendas serranas. Al apropiarse los mistis de ciertos símbolos indígenas, quizás se impidió que estos fuesen utilizados como emblemas políticos y de reivindicación.

\section{3. "Los procesos de cholificación".}

Las migraciones andinas hacia la costa empezaron en los años 50, y hasta ahora no se detienen pues involucran a los peruanos más pobres y de todos los pueblos del país.

Pero sobre todo a los habitantes de la sierra rural, pues ellos fueron los que la iniciaron, y ellos son los que están representados en la narrativa de la informalidad. ${ }^{10}$

Por eso una de las primeras tesis del antiguo Instituto de Etnología y Arqueología de San Marcos, sea la de Mildred Merino de Zela sobre el cerro San Cosme (1959) y que incluso, la tesis de bachillerato de Arguedas sobre el valle del Mantaro (1958) trate sobre la modernización de los pertinaces ayllus huancas, muy lejos del sur feudalizado del cual había sido testigo sufriente.

La modernización y la migración, fueron insumos de la cholificación. Es decir, un proceso de des-indianización masivo y de disolución de lazos corporativos de origen rural. Las demandas y las aspiraciones de estos nuevos "cholos" fueron ahora reclamados de manera individual

10 Véase Renatto Merino "Los discursos sobre los migrantes urbanos populares en Lima y la emergencia del sujeto democrático (1980-1992)" Tesis de licenciatura en Antropología, Lima: UNMSM, 2008. y adoptando los estándares de la vida urbana. Esto ha impedido la reformulación étnica y de su organización. Es decir una completa desmovilización que ha impedido cuajar movimientos políticos o sociales más amplios. La movilidad social ya no fue conquistada a través de demandas colectivas, sino con el esfuerzo atomizado de miles de migrantes que traen con ellos "el mito del progreso".

\section{TIPOLOGÍAS SOCIALES EN LA NARRATIVA MODERNA}

Es interesante el debate abierto sobre la convergencia entre la antropología y la narrativa literaria. Más aún cuando se considera que la etnografía (es decir el hecho de escribir una monografía) es en cierto modo, una narración. Algunos críticos del positivismo han ido más allá y consideran a esta clase de producción académica como un tipo de literatura (Clifford y Marcus 1991).

Otra variante ha sido la de representar a la cultura como un texto. En tal caso, el "escenario", los motivos del autor y la lógica interna del texto, han servido para revelar las razones no explícitas, que deberían aclarar la teoría cultural, las tramas sociales y el lugar etnográfico.

Así por ejemplo, The Kalela Dance (1956) de Mitchell, podría ser leído y analizado como un texto (enfatizando su contenido, su enunciación, su genealogía y su comparación con otros textos símiles), como una alegoría o quizás como una "ficción verdadera".

Esta convergencia también ha sido relacionada con las llamadas "novelas antropológicas"11 y la literatura de viajes, en donde lo inaudito y lo exótico son los mensajes más familiares que sintoniza la disciplina antropológica.

11 Adam Kuper (Antropología y antropólogos: la escuela británica 1870-1970. Barcelona. Anagrama, 1973: 139) menciona una novela de Joyce Cary (el autor de Mister Johnson, 1939) en donde la infortunada protagonista es una antropóloga norteamericana que desata fuerzas devastadoras que ella luego no puede controlar (An American Visitor, 1933) y que curiosamente esta en el capítulo dedicado al colonialismo. Del mismo modo podemos mencionar a El Hablador de Vargas Llosa (1987), en ella el protagonista Mascarita posee una triple marginalidad: un inmenso lunar en la cara, es judío de madre peruana y....estudia antropología. 
De igual modo uno podría encontrar claves "etnológicas" en novelas estrictamente de ficción. Por ejemplo Los ríos profundos (1956) ha sido objeto de múltiples exámenes (demasiados diría) de este tipo, generalmente referidos a la iniciación, la estructura social andina, las fábulas quechuas e incluso la linguística (recordemos el capítulo sobre el zumbayllu). La ruina del campesino ante el avance generalizado del capitalismo también podría ser graficada en célebres novelas como La uvas de la ira (1939) o Cuan verde era mi valle (1939).

En ese sentido, el análisis de Zunzunegui (2003) ha planteado que los géneros visuales como el documental y el cine deben ser considerados de ficción, aunque sólo el primero emita el sentido de veracidad, por sus estrategias persuasivas de enunciación.

Pues ambos materiales son reorganizados, editados, en muchas partes censurados, y emitidas para un público, una época y una moda: "la memoria es una pura trampa: corrige, sutilmente acomoda el pasado en función del presente" ha escrito Vargas Llosa en El Hablador. Así en Conversación en la Catedral (1969) la disposición de los acontecimientos no es histórica, pues se encuentran seleccionados y dispuestos por el discurso ideológico del autor.

Un caso notorio de esta hipótesis, es el conocido documental etnográfico "Las Hurdes" o "Tierra sin pan" de Buñuel (1932) en que autores como Pancorbo (1986) o Brisset (2006) intentan demostrar que casi todas las escenas filmadas fueron simuladas y representadas con una sobrecarga visual en que aflora la propaganda de agitación anarquista antes que el "realismo documental".

De igual modo, comparar una monografía antropológica con un texto de ficción no sería un intento de analogía desbordada. Pues se sostiene que el material de campo recogido por el antropólogo, es reorganizado post-facto, de acuerdo a exigencias teóricas e incluso de los lectores, ávidos de exotismos e historias reconfortantes sobre el "buen salvaje".12

12 Para Geertz (1998:13) la etnografía tiene entre otras características "la apariencia de verdad".

\section{Algunos ejemplos}

La literatura afro-norteamericana ha tenido la virtud de trascender el manifiesto extra-literario o la propaganda obvia, y se ha adentrado en el examen complejo del negro norteamericano.

Mas bien ha sido la "literatura blanca" en un primer momento, por el aprieto anti-esclavista es que desarrolló una narrativa urgente, en la que la dicotomía escueta-sobre todo en el Surse hace manifiesta. De La Cabaña del Tío Tom (1852), a Extraño Fruto de Lillian Smith (1944), los temores ocultos y los prejuicios se enraízan en una tierra común, moldeando la vida de sus habitantes.

Sin embargo es con Toni Morrison (premio Nóbel 1993), que la novela sobre la negritud es inundada no sólo de poesía sino de lúcida denuncia. Encaramada en la belleza del texto y de su sonoridad, es que quiero detenerme muy brevemente en su célebre novela Ojos Azules publicada en 1970.

Desgarradora, nos cuenta la historia de Pécola niña negra de Ohio, cuya existencia no la aparta de la pobreza y la violencia. Violada por su propio padre, termina perdiendo la razón, que opera como un refugio ante el inesperado estallido de la realidad en su dimensión más trágica.

Pero Pécola además, fantasea con tener los ojos azules y ser bella como su muñeca rubia. Su alma astillada por el racismo (se es fea por negra) sabe que el desprecio que sufre puede atenuarse con su propia negación. En la narrativa de Morrison, el negro es diseccionado con rabia. En esta novela, se cruzan firmemente, la temática del abuso y la explotación de los adultos sobre los niños, la inferiorización de la mujer negra y sobre todo el desprecio de los negros sobre los más negros.

En efecto, el negro no es visto como un conjunto homogéneo, sino atravesado por múltiples contradicciones en que las prácticas religiosas, el racismo, la estratificación social y sus subjetividades, crean una amalgama que enriquece las posibilidades de narración. Morrison crea una 
sutil distinción de la clase negra y su lograda diferencia, que como en una gradiente se van mezclando desde las tonalidades del color hasta su ubicación social:

"Vienen de Mobile. De Aiken. De Newport News. De Marieta. Y el nombre de aquellos lugares, pronunciado por sus bocas, te hacen pensar en el amor. Cuando les preguntas de donde son inclinan la cabeza y dicen: "Móbile" y crees que te han besado. Dicen: "Aiken", y tu ves una mariposa blanca que, con un ala rota, elude el choque con una verja. Dicen "Nagadoches", y tu anhelas decir: "Si quiero."

"No son irritables, nerviosas ni chillonas; no tienen adorables cuellos negros, que estiran como para liberarse de un collar invisible; sus ojos no muerden. Esas chicas de Mobile, azúcar moreno andan por la calle sin meneo ni alboroto. Son tan suaves, tan sencillas como un dulce de nata. Tobillos delgados; largos, estrechos pies. Se lavan con jabón Lifebuoy de color naranja, se empolvan con talco Cashmere Bouquet, se lavan los dientes con un trapo impregnado de sal, se suavizan la piel con loción Jergens."

"Son esbeltas morenas que han mirado mucho las malvarrosas que crecen en los Jardines de Meridian, de Mobile, de Aiken, de Baton Rouge. Y que como las Malvarrosas, son prietas, altas y apacibles. Tienen raíces profundas, tallos firmes, y sólo la flor que las corona cabecea al viento. Poseen los ojos de las personas que saben la hora que es por el color del cielo. Esas chicas viven en tranquilos barrios negros donde todo el mundo esta bien empleado. Donde en los porches hay balancines colgados de cadenas. Donde el césped se corta con guadaña, donde se yergue el gallo y en el patio crecen girasoles y en los peldaños y los antepechos de las ventanas se alinean tiestos de fucsias, de hiedra, de sensivieras".

"Le había explicado la diferencia entre personas de color y negritos. Unas y otras eran fácilmente identificables. Las personas de color eran discretas y limpias; los negritos eran sucios y ruidosos. Él pertenecía al primer grupo: vestía camisas blancas y pantalones azules (..) La línea divisoria entre persona de color y negrito no siempre era concluyente: sutiles signos reveladores amenazaban con difuminarla y había que permanecer constantemente alerta." 13

La vida placentera pero llena de grietas de la burguesía negra que es mostrada en Paraíso (1999) o la esclavitud como el imperio de lo irracional en Beloved (1987), muestra a Morrison como la juglar de esa vastedad, que apenas los estudios sociológicos han mostrado. Muy lejos por supuesto, del "yo" confuso y desorientado que aparece en El Hombre Invisible (1952) de Ralph Ellison. Esta vez ya no es el sur, sino los guetos negros del norte industrial, en donde la ausencia -su invisibilidad- es duplicada en la gran urbe.

Más bien enlazada con la tradición de protesta, Otro País (1962) de James Baldwin, se revela como una novela soberbia y lacerante del mundo negro, en que el lirismo religioso, el sexo y la supervivencia es el escenario por la que se odian blancos y negros, a la vez que se necesitan.

Menos divertidos por supuesto que los detectives únicos, Sepulturero Jones y Ataúd Johnson, los más negros de la novela negra rodando por la variopinta Harlem, que inmortalizó Chester Himes. ${ }^{14}$

Arundhati Roy ha sabido condensar la estructura irradiada de clase, casta, comunidad y género de la India en El Dios de las Pequeñas Cosas (1997).

13 Toni Morrison. Ojos Azules. Barcelona. Plaza \& Janés, 2001: 103, 110.

14 Por amor a Imabelle. Barcelona: Bruguera, 1980 y Algodón en Harlem. Barcelona: Grijalbo, 1995, son dos novelas en las que uno encuentra la misma sensación: una mirada negra de la sociedad negra, que en su intimidad esconden las mismas pasiones y fantasías de los blancos. Al igual que las sureñas de Morrison, el conjunto negro es mostrado aquí en su profunda versatilidad. 
Al igual que en la novela de Morrison, privilegia la mirada de los niños para captar la tragedia que desencadena la colisión entre la tradición y la modernidad en Kerala.

Vista también como una saga familiar centrada en la ciudad de Kottayam, nos narra la historia de niños mellizos separados y desgarrados por el pecado de la madre, convertida en amante de un joven de casta inferior. Ammu la madre, es reducida a ser protagonista de una tragedia manejada por una urdimbre ajena a ella. Trama construida por los hombres y sancionada por un poder local que ha hecho de la jerarquía no sólo el testigo de la decadencia de su familia, sino también en parte, de la India tradicional.

No obstante que la estructura de castas alentó la imaginación occidental, a tal punto que la antropología fue disciplinada por el fenómeno. La profunda religiosidad y el sistema de castas fueron por así decirlo, casi sinónimos y ejemplares en el examen de la India contemporánea. ${ }^{15}$

No obstante que este sistema peculiar de estratificación fue cuestionado casi en el mismo momento de su gestación por las filosofías materialistas y escépticas de hace casi mil años, ha gravitado sin embargo, en los momentos más importantes y significativos del sub-continente. Así sucede en la costa suroeste:

"Pappachi no permitía que los paravanes entraran en la casa. Nadie lo hacia. No se les permitía tocar nada que los Tocables pudieran tocar. No se lo permitían los de las Castas Hindúes ni los de las Castas Cristianas. Mammachi les contó a Esthay a Rahel que se acordaba de la época en que, siendo niña, los paravanes tenían que retro-

15 Appadurai también ha cuestionado en algún momento la lógica de la antropología occidental de confundir el tema con el lugar. Amartya Sen lo dice precisamente: "el hecho de juzgar las tradiciones indias como mayoritariamente religiosas, profundamente anticientíficas, exclusivamente jerárquicas o fundamentalmente no escépticas (...) implica una significativa y excesiva simplificación del pasado y el presente de la India" (2007: 56). ceder de rodillas, borrando sus huellas con una escobilla, para que los brahmanes o los cristianos sirios no se volvieran impuros al pisar sin querer sus pisadas. En tiempos de la niñez de Mammachi no se permitía a los paravanes, igual que a los demás Intocables, andar por la vía pública, ni cubrirse la parte superior del cuerpo, ni usar paraguas. Cuando hablaban, tenían que taparse la boca con la mano, para evitar que su aliento contagiase su impureza a aquellos a quienes dirigían la palabra.”

"Cuando los británicos llegaron a lo que hoy es Kerala, muchos paravanes, pelayas y peluyas (entre ellos Kelan, el abuelo de Velutha) se convirtieron al cristianismo e ingresaron en la Iglesia anglicana para escapar al flagelo de la Intocabilidad (...) No les llevó mucho tiempo darse cuenta de que habían salido del fuego para caer en las brasas. Los obligaron a tener iglesias separadas, con ceremonias separadas y sacerdotes separados (...) Después de la Independencia se encontraron con que no tenían acceso a las prestaciones estatales para los Intocables, como reservas de puestos de trabajo o derecho a obtener préstamos bancarios a bajo interés, ya que oficialmente estaban censados como cristianos y por lo tanto fuera del sistema de castas. Era algo así como tener que borrar las propias huellas sin escobilla. $\mathrm{O}$, peor aún, que ni siquiera se les permitiese dejar huellas." (subrayado de la autora) ${ }^{16}$

Vulnerar el tabú no es negarlo sino trascenderlo y completarlo, escribió Bataille. Los amores de Ammu cristiana savarna y Velutha el intocable, a orillas del río -ese ancho río en que se inicia y concluye la tragedia- rasgan un sistema de opresiones en que los individuos no son iguales sino confrontados en una jerarquía inmutable. La ruptura y la trasgresión entonces, se revelan a la novelista como el ascenso de un nuevo sol:

16 Arundhati Roy. El dios de las pequeñas cosas. Barcelona. Anagrama, 1998: 95-96. 
"Siglos enteros quedaron plegados como un acordeón en un momento único y fugaz. La Historia fue cogida a contrapelo, desprevenida. Despojada de su piel como una vieja serpiente. Sus marcas, sus cicatrices, sus heridas de antiguas guerras y los días en que tenían que retroceder de rodillas, todo, cayó al suelo. Al desaparecer dejó un aura, un resplandor palpable que era tan fácil de ver como el agua en un río o el sol en el cielo. Tan fácil de sentir como el calor en un día caluroso, o el tirón de un pez en un sedal tenso." (1998:207-208).

Esa revelación tiene en el final de la novela, un hálito de esperanza: mañana.

Así como Heinrich Boll ha sido llamado el "narrador de los escombros" por mostrarnos la Alemania de la post-guerra, José Donoso se caracteriza por describir en una especie de saga, la decadencia de la oligarquía chilena.

Por ejemplo en Día Domingo (1966), la casa es representada como una metáfora de la lenta pero inexorable decrepitud de una clase y de una época. Pero es sobre todo con El Obsceno Pájaro de la Noche (1970) que no sólo incorpora a la narrativa chilena de lleno en el boom latinoamericano, sino que agudiza su visión sobre la decadencia llevada hasta el absurdo.

En esta impresionante novela, es la casa y los cuerpos las que nos muestran el paso del tiempo, dotándonos de una fantástica historia del envilecimiento que otorga la edad y la decadencia. Es también la negación de la historia única. $\mathrm{Al}$ enclaustramiento físico y social de los personajes, se muestra una multitud de voces subalternas (las sirvientas decrépitas, los rotos del campo y la ciudad, los monstruos). Estas múltiples historias -Donoso mismo calificó su novela de polifónica y "coral"- pugnan simultáneamente por adeñuarse del texto.

La subalternidad entonces no sólo se confina en la desigualdad social sino sobre todo, en la hegemonía de la historia que trata de imponerse. Al final son el Mudo o Humberto Peñaloza hombres grises, ex-sirvientes y sin historias, los que se adueñan finalmente de la historia imprimiéndole su desesperanza:

"Los servidores acumulan los privilegios de la miseria. Las conmiseraciones, las burlas, las limosnas, las ayuditas, las humillaciones que soportan los hacen poderosos. Ellas conservan los instrumentos de la venganza porque van acumulando en sus manos ásperas y verrugosas esa otra mitad de sus patrones, la mitad inútil, descartada, lo sucio y lo feo que ellos, confiados y sentimentales, les han ido entregando con el insulto de cada enagua gastada que les regalan, cada camisa chamuscada por la plancha que les permiten que se lleven (...) Ellas barrieron de sus comedores las migas caídas y lavaron los platos y las fuentes y los cubiertos, comiéndose lo que sobró. Limpiaron el polvo de sus salones, las hilachas de sus costuras, los papeles arrugados de sus escritorios y oficinas. Reestablecieron el orden en las camas donde hicieron el amor legítimo o ilegítimo, satisfactorio o frustrador, sin sentir asco ante esos olores y manchas ajenos. Cosieron los jirones de sus ropas, les sonaron las narices cuando niños, los acostaron cuando llegaron borrachos y limpiaron sus vómitos y meados, zurcieron sus calcetines y lustraron sus zapatos, les cortaron las uñas y los callos, les escobillaron la espalda en el baño, los peinaron, les pusieron lavativas y les dieron purgantes y tisanas para la fatiga, el cólico o la pena. Desempeñando estos menesteres las viejas fueron robándose algo integral de las personas de sus patrones al colocarse en su lugar para hacer algo que ellos se negaban a hacer...y la avidez de ellas crece al ir apoderándose de más cosas, y codician más humillaciones y más calcetines viejos regalados como dádivas, quieren apoderarse de todo" 17

Si en El Obsceno Pájaro de la Noche la distorsión es la norma, en El Jardín de al lado (1981) es la sensación del desdoblamiento. Gloria siendo la novelista trasvertida ante el

17 José Donoso. El Obsceno Pájaro de la Noche. Barcelona. Seix Barral, 1974: 64-65. 
fracaso literario de Julio. Es Julio anhelando el cuerpo del "angelo musicante", de ser él, en una playa catalana. De reconocerse en los ojos del joven mendigo de Marrakech. Es también el deseo de poseer la inalcanzable condesa en el jardín de al lado, en un tórrido verano de Madrid.

Aquí la experiencia del exilio latinoamericano es abordada de manera tragicómica, la noción del país dejado y la convivencia mutua en suelo europeo, nos indica una permanente búsqueda de identidad en una suerte de desdoblamiento colectivo:

"Uno no vuelve a un país, a una raza, a una idea, a un pueblo: uno -yo por lo prontovuelve a un lugar cerrado y limitado donde el corazón se siente seguro"- piensa Julio Méndez. ${ }^{18}$

\section{FACETTA NERA}

En las discusiones teóricas que se suscitaron en el seno del socialismo italiano en el primer tercio del siglo XX, se privilegió un asunto que inspiró la discusión del carácter de Italia como nación. En esa notable discusión de los intelectuales marxistas de Turín, se debatió el llamado "problema meridional." Es decir, la explotación del sur pobre y campesino en la Italia del "risorgimiento".

En su discusión, destacaba Emilio Sereni, cuya obra teórica estuvo dedicada a estudiar lo que denominó el colonialismo interno. Es decir, la mano de obra barata expulsada del campo hacia las urbes industriales del Po. La crisis de los sistemas patriarcales y latifundistas, que explicaban el trasvase del plustrabajo campesino, la exportación de remesas y la migración como componentes esenciales del capitalismo rural. ${ }^{19}$

Dichos trabajos fueron útiles para entender desde entonces, las lógicas del capitalismo periférico en el llamado hemisferio sur. El colonialismo interno pues poseía temas políticos, sociales

18 El Jardín de al lado. Madrid. Espasa, 2003: 171.

19 Emilio Sereni. Il capitalismo nelle campagne (1860. 1900). Torino. Eunaudi, 1971. y culturales que abordar.

La novela de Carlo Levi va en ese sentido. Visto no sólo como el testimonio de un médico y pintor italiano confinado en Lucania por sus actividades anti-fascistas en 1935, sino sobre todo, como páginas de reflexión personal, de esperanza política y testimonio etnográfico excepcional del sur italiano.

Cristo se paró en Eboli (1945) muestra tipos y acontecimientos que sólo una persona con compromiso político y curiosidad sociológica puede realizar. Los caciques, policías, jerarcas fascistas y sobre todo los miserables campesinos son mostrados como en una paleta. Los rostros oprimidos, desgarrados y desdentados quizás nos recuerden a los campesinos rusos de Tolstoi o los pongos de Arguedas:

"Esta pasiva fraternidad, este padecer conjuntamente, esta resignada solidaridad, esta secular paciencia es el sentimiento común de los campesinos, vínculo no religioso, sino natural. Ellos no poseen, ni pueden poseer, lo que suele llamarse consciencia política, porque son, en todos los sentidos del término, paganos y no ciudadanos. Los dioses del Estado y los de la ciudad no pueden ser objeto de culto entre estas tierras arcillosas en las que reina el lobo y el antiguo y negro jabalí. No hay muro que separe el mundo de los hombres del de los animales y del de los espíritus, ni las frondas de los árboles visibles de las oscuras raíces subterráneas. No pueden poseer ni siquiera una consciencia individual, donde todo esta ligado por influencias recíprocas, donde cada cosa es un poder que obra insensiblemente, donde no existen límites que no sean rotos por un mágico influjo. Ellos viven inmersos en un mundo que se sucede a si mismo sin determinaciones, donde el hombre no se distingue de su sol, de su animal, de su malaria; donde no puede existir la felicidad, codiciada por los literatos paganizantes, ni la esperanza, que son, en todo caso, sentimientos individuales, sino la oscura pasividad de una naturaleza dolorosa. Pero en ellos esta vivo 
el sentido humano de un destino común y de una común aceptación" 20

El campesino esta nutrido de fatalismo ante poderes externos y omnipotentes, es conservador y percibe las injusticias no como el acceso desigual a la riqueza, sino como una multiplicación de los deseos que hay que evitar.

La sentencia de Levi pues, nos evoca las afirmaciones de Foster quien divisó a los campesinos latinoamericanos y españoles con ese sentimiento de pasividad y de su ulterior aversión al cambio y a la modernización.

En síntesis creemos que la teoría étnica, sus ámbitos discursivos y los tipos sociales que nos concede la narrativa moderna pueden ser escenarios privilegiados para reflexionar y re-crear la creatividad con la reflexión sociológica.

\section{BIBLIOGRAFÍA}

Adams, Richard N.

1993 Etnicidades internas y externas: con una referencia especial a América central. Austin. Universidad de Texas.

Benedict, Burton

1989 "Características de los pequeños territorios y sus repercusiones en el desarrollo económico". En Antropología de las sociedades complejas, Michael Banton, Comp. Madrid. Alianza Editorial.

Barth, Fredrik

1976 Los grupos étnicos y sus fronteras: la organización social de las diferencias culturales. México. Fondo de Cultura Económica.

Berghe, den van Pierre

1973 "El uso de términos étnicos en la literatura de ciencias sociales del Perú". En Allpanchis (5): 5-18.

Brisset Martín, Demetrio

2006 "Imágenes de la muerte en "Las Hurdes" de Buñuel: Aproximación desde la Antropología visual". En Gazeta de Antropología(22).

20 Carlo Levi. Cristo se paró en Eboli. Madrid. Alfaguara, 1980: 95-96.
Clifford James y Marcus, George (Eds.)

1991 Retóricas de la etnografía. Madrid. Júcar.

Contreras, Carlos

1988 Mineros y campesinos en los Andes: mercado laboral y economía campesina en la sierra central, siglo XIX. Lima. IEP.

Cortázar Velarde, Juan Carlos

1992 "El paradigma de la intersubjetividad en las ciencias sociales peruanas: un panorama breve". En Debates en Sociologia (17): 163-206.

Favre, Henri

1983/1985 "El mundo Andino en tiempos de Bolívar. Los Asto entre 1780 y 1830". En Revista del Museo Nacional (47): 259. 271.

García Miranda, Juan J.

1991 Huamanga en los cantos de arrieros y viajantes. Lima. Lluvia.

Garma Navarro, Carlos

1987 Protestantismo en una comunidad totonaca de Puebla. México. Instituto Nacional Indigenista, 1988.

Geertz, Clifford

1998 El antropólogo como autor. Barcelona. Paidós.

Kuper, Adam

2001 Cultura: la versión de los antropólogos. Barcelona. Paidós.

Lauer, Mirko

1997 Discursos del indigenismo. 2. Lima. Sur.

Manrique, Nelson

1988 Yawar Mayu: Sociedades terratenientes serranas 1879-1910. Lima. Desco.

Neira, Hugo

1964 Cuzco: Tierra y Muerte. Lima. Populibros.

Ossio, Juan

1978 "Relaciones interétnicas y verticalidad en los Andes". En Debates en Antropología (2)

Pajuelo, Ramón

2006 Participación política indígena en la sierra peruana: una aproximación desde las dinámicas sociales y locales. Lima: IEP/Konrad Adenauer.

Pancorbo, Luís

1986 La Tribu Televisiva: análisis del documental 
etnográfico. Madrid. Instituto Español de Radio y Televisión.

Pitt-Rivers, Julián

1976 "Sobre la palabra 'casta". En America Indigena (36): 559-586.

Plasencia, Rommel

2005 “Existe la cultura andina?". En Revista de Antropologia (3):275-282

Reynoso, Carlos

2000 Apogeo y decadencia de los estudios culturales: una aproximación antropológica. Barcelona. Gedisa.

Sen, Amartya

2007 India Contemporánea. Entre la modernidad y la tradición. Barcelona. Gedisa.
Stefanoni, Pablo

2007 "Siete preguntas y siete respuestas sobre la Bolivia de Evo Morales". En Nueva Sociedad (209): 46-65.

Weiss, Gerald

2005 "Los campa ribereños". En Guía Etnográfica de la Alta Amazonía, Fernando Santos y Federica Barclay, comp. Vol.5: 7-40. Balboa: Smithsonian Tropical Research Institute/IFEA.

Zunzunegui, Santos

2003 Pensar la imagen. Madrid. Cátedra/Universidad del País Vasco. 